Western University

Scholarship@Western

Aboriginal Policy Research Consortium International (APRCi)

2011

\title{
Stigmatization as a Social Control Mechanism for Persons Living with HIV and AIDS
}

Judy E. Mill

Nancy Edwards

Randy C. Jackson

Lynne MacLean

Jean Chaw-Kant

Follow this and additional works at: https://ir.lib.uwo.ca/aprci

Part of the Medicine and Health Commons

Citation of this paper:

Mill, Judy E.; Edwards, Nancy; Jackson, Randy C.; MacLean, Lynne; and Chaw-Kant, Jean, "Stigmatization as a Social Control Mechanism for Persons Living with HIV and AIDS" (2011). Aboriginal Policy Research Consortium International (APRCi). 231.

https://ir.lib.uwo.ca/aprci/231 


\section{Qualitative Health Research}

http://qhr.sagepub.com/

Stigmatization as a Social Control Mechanism for Persons Living with HIV and AIDS

Judy E. Mill, Nancy Edwards, Randy C. Jackson, Lynne MacLean and Jean Chaw-Kant

Qual Health Res 2010 20: 1469 originally published online 27 July 2010

DOI: $10.1177 / 1049732310375436$

The online version of this article can be found at:

http://qhr.sagepub.com/content/20/11/1469

\section{Published by: \\ (S)SAGE}

http://www.sagepublications.com

Additional services and information for Qualitative Health Research can be found at:

Email Alerts: http://qhr.sagepub.com/cgi/alerts

Subscriptions: http://qhr.sagepub.com/subscriptions

Reprints: http://www.sagepub.com/journalsReprints.nav

Permissions: http://www.sagepub.com/journalsPermissions.nav

Citations: http://qhr.sagepub.com/content/20/11/1469.refs.html

>> Version of Record - Oct 20, 2010

OnlineFirst Version of Record - Jul 27, 2010

What is This? 


\title{
Stigmatization as a Social Control Mechanism for Persons Living with HIV and AIDS
}

\author{
Judy E. Mill,' Nancy Edwards, ${ }^{2}$ Randy C. Jackson, ${ }^{3}$ \\ Lynne MacLean, ${ }^{2}$ and Jean Chaw-Kant ${ }^{\prime}$
}

\begin{abstract}
Stigmatization contributes to inequity by marginalizing persons living with HIV and AIDS (PHAs). In this study we examined the stigmatizing practices in health care settings from the perspectives of PHAs and health care providers (HCPs). A qualitative design, using a participatory action research approach, was used. Interviews and focus groups were completed with 16 aboriginal and 17 nonaboriginal individuals living with HIV (APHAs and PHAs) and 27 HCPs in Ottawa and Edmonton, Canada. We present findings to support the premise that stigmatization can be used as a social control mechanism with PHAs. Participants described both active and passive social control mechanisms: shunning and ostracizing, labeling, and disempowering health care practices. Forgiving behavior, balancing disclosure, practicing universal precautions, bending the rules, shifting services, and reducing labeling were strategies to manage, resist, and mitigate social control. The findings illustrate the urgent need for multilevel interventions to manage, resist, and mitigate stigma.
\end{abstract}

\section{Keywords}

aboriginal people, North America; health care, access to; HIVIAIDS; research, qualitative; stigma; theory development

Early in the AIDS epidemic Dr. Jonathon Mann, founder of the World Health Organization's Global Program on AIDS, argued that AIDS was not strictly a medical condition, but an illness with profound social, cultural, economic, and political dimensions (Fee \& Parry, 2008; Mann $\&$ Carballo, 1989). He referred to this phenomenon as the third AIDS epidemic, encompassing the denial, blame, stigmatization, and discrimination that HIV and AIDS evoke. The Panos Institute (1990) argued that the third epidemic has resulted in repercussions in virtually all societies affected by HIV, "challenging our compassion, our judgment, and our humanity" (p. ii). More than 20 years after Dr. Mann's insightful comments, structural inequities such as poverty, racism, gender inequality, power imbalance, and sexual oppression continue to intersect and shape the HIV epidemic (Gupta, Parkhurst, Ogden, Aggleton, \& Mahal, 2008; Parker \& Aggleton, 2003), and the suffering caused by AIDS stigma and discrimination remain. This reality presents significant challenges to the development of interventions for HIV prevention and AIDS care.

As illnesses, HIV and AIDS elicit profound stigma. Several of the attributes of HIV illness increase the likelihood that its victims will be stigmatized: (a) the illness is viewed as the result of individuals violating the moral order of society (Alonzo \& Reynolds, 1995; Mwinituo \& Mill, 2006; Scott, 2009); (b) the contagiousness of HIV illness is perceived to threaten society (Mawar, Saha, Pandit, \& Mahajan, 2005; Mill, 2003); (c) HIV illness is viewed as a debilitating disease that results in death (Des Jarlais, Galea, Tracy, Tross, \& Vlahov, 2006; Mill, 2003; Scott); (d) the symptoms of HIV illness become visible as the disease progresses (Hawkins, 2006); (e) it is transmitted sexually (Mwinituo \& Mill); and (f) HIV illness has most frequently been associated with groups already marginalized in society (Mawar et al.; Mill et al., 2009). AIDS stigma has the potential to influence health and healthseeking behaviors in a variety of ways and, therefore, is an important consideration for health care professionals. For

'University of Alberta, Edmonton, Alberta, Canada

${ }^{2}$ University of Ottawa, Ottawa, Ontario, Canada

${ }^{3}$ McMaster University, Hamilton, Ontario, Canada

\section{Corresponding Author:}

Judy Mill, Faculty of Nursing, University of Alberta, 7-90 University

Terrace Edmonton, Alberta, T6G 2T4 Canada

Email: judy.mill@ualberta.ca 
example, stigmatized conditions might result in individuals and caretakers concealing their illness (Mill et al., 2009; Mwinituo \& Mill). Concealment, a behavior that enables persons living with HIV to have some control over their lives, has profound implications for the individual, and in the case of stigmatized conditions that are infectious, has additional implications for public health (Des Jarlais et al.).

Despite recognition early in the epidemic that "AIDS makes explicit ... the complex interaction of social, cultural, and biological forces" (Brandt, 1987, p. 199), AIDS stigma has long been conceptualized as a personal attribute that evokes discrimination. The conceptualization of AIDS stigma must be broadened from the notion that stigma is a relatively static individual attribute to include recognition that it is "intimately linked to the reproduction of social difference" (Parker \& Aggleton, 2003, p. 13), and is therefore ultimately a mechanism for social control. Furthermore, there is a need to understand how stigma influences professional and organizational practice and permeates health policy. This understanding must be predicated on the development and refinement of theory to describe AIDS stigma and discrimination (Campbell \& Deacon, 2006; Deacon, 2006; Holzemer, Uys, Makoae, et al., 2007; Parker \& Aggleton; Taylor, 2001).

Early definitions of stigma reinforced the notion that stigma was an individual attribute. Goffman described stigma as "an attribute that is deeply discrediting" (1963, p. 13). The focus of stigmatization at the individual level is also seen in later definitions, including those of Alonzo and Reynolds (1995) and Siyam'kela (2006). These definitions provide some broadening of the concept of stigma, recognizing both emic and etic perspectives of the phenomenon. Despite this evolution, these theories still emphasized the individual with HIV or AIDS as the source of stigma, with limited attention to the structural inequities that influence the manifestation and experience of stigma. Parker and Aggleton (2003) argued that there has been very limited conceptualization of stigma beyond the individual level. Thus, there is a concentration of individually focused etiological and intervention research, with limited attention paid to the larger structural conditions that create exclusionary practices. Stigma has often been viewed as a negative element, mapped onto people rather than onto social institutions (Parker \& Aggleton), reinforcing the perception that stigma is a static attribute rather than a social process. Although some recent work has acknowledged the wider social processes influencing stigma, there remains a tendency to revert back to an individualistic perspective on stigma. Holzemer, Uys, Makoae, and colleagues (2007) identified the need to describe the larger societal context of AIDS stigma in Africa; however, their discussion of the "stigma process" (p. 546) remains rooted in an individualistic approach.

Several authors have critiqued conceptualizations of stigma that focus primarily on the individual level in relation to AIDS (Parker \& Aggleton, 2003; Yang et al., 2007), diabetes (Aikins, 2006), and hepatitis $C$ (Paterson, Backmund, Hirsch, \& Yim, 2007). Parker and Aggleton provided a compelling case for expanding the conceptualization to include the political and societal dimensions of stigma, and to reflect power dimensions that are at play in society. In relation to HIV status, stigma reflects inequitable power relations that are "created and sustained to legitimize dominant groups in society" (International Federation of Red Cross and Red Crescent Societies, 2004, p. 70). Parker and Aggleton described stigmatization as "culturally constituted" and "central to the establishment and maintenance of social order" (p. 17). Similarly, Taylor (2001) argued that "stigma serves to reinforce social norms by defining deviance" (p. 794), thereby promoting inequity by marginalizing an individual or group from the rest of society.

Campbell and Deacon (2006) argued that conceptualizations of stigma must merge both the individual and social dimensions of stigma, rather than predisposing toward either dimension. The authors provided a critique of individualistic explanations of stigma; however, they cautioned that focusing only on the macrolevel analysis of stigma might result in the individual psychological dimensions receiving inadequate attention. Therefore, they proposed a conceptualization of stigma that "straddles individual and macro-social analysis" (p. 412) to ensure a more comprehensive understanding of the phenomenon. They suggested that although stigma is embedded in the individual psyche, it is continually influenced by material, political, institutional, and symbolic contexts.

Illnesses, and particularly those that are considered the result of deviant behavior (e.g., AIDS, leprosy), represent a threat to the established order of society (Freund $\&$ McGuire, 1998). Shapiro argued that from a Western biomedical perspective, "the role of medicine is to contain and manage the potential chaos of illness from overwhelming the social fabric" (2008, p. 3). Social control mechanisms such as stigma therefore assist in maintaining societal order. For example, health care providers (HCPs), in positions of power, influence the labeling of deviance and the establishment of social norms (Freund $\&$ McGuire).

Individuals already marginalized in society, and who develop a stigmatizing condition such as HIV infection, might experience a layering or double burden of stigma (Duffy, 2005; Mill et al., 2009; Mill, 2001; Reidpath \& Chan, 2005; Weiss \& Ramakrishna, 2001). Indigenous peoples worldwide have a history of being disadvantaged 
and marginalized within both poor and wealthy countries, with consistently poorer health outcomes than their nonindigenous counterparts in the same country (Gracey \& King, 2009; Stephens, Porter, Nettleton, \& Willis, 2006). In the Canadian aboriginal population, the long history of racism, marginalization, colonization, and disenfranchisement (Adelson, 2005; King, Smith, \& Gracey, 2009; Larkin et al., 2007; Pearce et al., 2008) has resulted in a greater likelihood that if HIV positive, they will experience a layering of stigma. Reidpath and Chan suggested that "there needs to be an understanding of the layering of stigma so that informed policies and interventions can be developed that will address the entire experience of stigma" (p. 431). Aboriginal people might be differentially impacted by HIV infection because of varying cultural constructions of stigma; differing beliefs about health, illness, and healing; and the burden of having more than one attribute that evokes stigma (Weiss \& Ramakrishna).

In Canada, aboriginal peoples experience a high burden of disease and social suffering (Adelson, 2005; Larkin et al., 2007); it is estimated that the HIV infection rate among the Canadian aboriginal population is 2.8 times higher than among nonaboriginal persons (Boulos, Yan, Schanzer, Remis, \& Archibald, 2006). Although only $3.8 \%$ of the Canadian population report aboriginal ancestry (Statistics Canada, 2008), in 2006 aboriginal persons made up 24.4\% of AIDS cases for which ethnicity was known (Public Health Agency of Canada, 2007). Adelson argued that the health disparities experienced by the aboriginal peoples in Canada are the "embodiment of inequity" (p. S45), and that these disparities are related to economic, political, and social inequities, including limited autonomy.

Das argued that "discourses on stigma are deeply implicated in the fault lines of racism, sexism and other forms of discrimination" (2001, p. 9). For example, poverty might magnify and drive the stigmatization of persons living with HIV and AIDS (Campbell, Nair, Maimane, \& Nicholson, 2007; Masanjala, 2007), limiting one's ability to resist stigma (Campbell \& Deacon, 2006). The phenomenon of layered stigma suggests that stigma might follow the path of existing fault lines (Campbell \& Deacon); however, it might also create new ones (Deacon, 2006). The notion that some groups in society are less vulnerable to stigma than others was explored with HIV-positive women who were not considered marginalized, but rather, possessed one or more signs of "symbolic capital," including being White, heterosexual, educated, and/or middle class (Grove \& Kelly, 1997). Symbolic capital provided some protection against stigma.

The purposes of our current study were (a) to explore stigmatizing practices in health care settings from the perspectives of PHAs, APHAs, and HCPs; (b) to develop an optimal design for health service delivery to eliminate stigmatizing practices; and (c) to describe the process required to reorient health services to incorporate the optimal design. In this article we present findings related to the first purpose of the study. The findings related to the second and third purposes will be the subject of a future article. Based on the analysis of the stigmatizing practices that PHAs and APHAs encountered when accessing health care settings, we argue that stigma can be conceptualized as a social control mechanism that is used implicitly or explicitly by individuals, organizations, and society.

\section{Methods}

A qualitative design, using a participatory action research (PAR) approach was used for the study. This approach facilitates consciousness raising and promotes critical thinking in individuals and communities to explore the root causes of their situation (Schoepf, 1994). The tenets of PAR are congruent with the essential principles for the conduct of research with aboriginal communities: ownership, control, access, and possession (OCAP; Patterson, Jackson, \& Edwards, 2006); the protection of indigenous knowledge (Battiste \& Henderson, 2000); consideration of ethical implications for individuals and communities (Kaufert et al., 2001); and the adherence to communitycontrolled collaboration (Smylie et al., 2004). Throughout the research process, several strategies were used to develop and maintain a collaborative relationship with our community partners. In Edmonton, ethical approval was obtained from the Health Ethics Review Board (Panel B) at the University of Alberta, to access sites in Edmonton. In Ottawa, ethical approval was obtained from the Ottawa hospital, general site, and the University of Ottawa. After ethical approval was obtained, community advisory committees were formed at each site to advise on the implementation process, cultural appropriateness of guiding questions, and dissemination strategies for the study. The community advisory committees included PHAs and APHAs; and representatives from aboriginal communities, agencies offering services to PHAs and APHAs, and consumer groups representing PHAs and APHAs. Terms of reference for the community advisory committees were developed by the research team in consultation with the community advisory committee members.

Community consultation workshops were another strategy used to engage our community partners. Following preliminary data analysis, 1-day workshops were held with 97 participants in three Canadian cities. The participants included PHAs, APHAs, community advisory committee members, HCPs, representatives from AIDS 
service organizations, decision makers, and research team members. The purpose of the workshops was to engage decision makers and HCPs in the design of an intervention to reduce AIDS stigma in health services for PHAs and APHAs. During the workshops, members of the research team provided an overview of key findings from the research project, and then workshop participants were asked to assist with the design of an intervention. Bestpractice guidelines (Mill et al., 2007) for the provision of services to PHAs and APHAs were an outcome of this process, and will be published separately.

A multiorganizational design was used to enhance our understanding of the context of AIDS stigma in different settings. Convenience and network sampling (Wood \& Ross-Kerr, 2006) were used to recruit aboriginals and nonaboriginals to participate in an interview in the cities of Edmonton and Ottawa, Canada. Aboriginal participants included individuals who identified as Métis, First Nations, or Inuit, regardless of treaty status (Ermine, Sinclair, \& Jeffrey, 2004). At each site, four health care organizations representing small and large organizations, using a range of approaches to health care delivery (e.g., acute care, primary health care), and providing access to aboriginal populations were selected to assist with recruitment of PHAs and APHAs. This helped to ensure that aboriginal peoples, who are overrepresented in the HIV and AIDS statistics (Public Health Agency of Canada, 2007), were included in the sample. The eligibility criteria for PHAs and APHAs required that participants be more than 18 years of age; agree to participate in the study; speak English or French; be HIV positive; not currently be an inpatient; had lived in Canada for at least 3 years; and had accessed health services (e.g., medical, dental, laboratory, x-ray, counseling) within the previous 2 years.

A contact person at each organization approached potential participants who met the eligibility criteria to ask if they were interested in participating in the study. Information letters were provided to potential participants, who were asked to contact the research coordinator. Open-ended interviews with PHAs and HCPs were conducted primarily by the research coordinator at each site, and focus groups with HCPs were carried out by two members of the research team in one of the participating organizations. Informed consent was obtained from all participants. The contact person at each of the participating organizations was consulted to determine if interviews or focus groups for the HCP would be preferable. Inclusion criteria for the HCPs required that they be English or French speaking, a health professional or community worker in one of the organizations participating in the study, and agree to participate in the study. Guiding questions were prepared to assist the interviewer to focus the interviews on the experiences of the participants in relation to stigma and to maintain a balance between consistency and flexibility (May, 1991). The HCPs were asked to reflect on the themes emerging from the interviews with APHAs and PHAs in relation to stigmatizing practices; however, HCPs were not asked to comment on social control mechanisms. Concurrent with the interviews and focus groups with HCPs, the policies and practices of organizations were also examined to identify those that might promote or inhibit AIDS stigma. The document analysis was carried out to uncover the perspectives and priorities of each of the participating organizations in relation to the care and treatment of persons with HIV. Document analyses are appropriate for gathering information about the context for implementing new policies or practices (Murphy, 2001).

An inductive approach was used to analyze the data from the PHA and APHA interviews and involved coding and identifying categories and themes and discovering and disconfirming relationships among themes via systematic comparisons using matrices, negative cases, and extreme cases. The focus groups and interviews with HCPs were similarly analyzed, and findings compared to the issues emerging from the data from PHAs and APHAs. During the initial, descriptive analysis of the study findings, the AIDS stigma experienced by participants often intersected with other forms of stigma related to behavior, culture, gender, sexual orientation, or social class, and organizational policies contributed to and intersected with individual stigma (Mill et al., 2009). An in-depth conceptual analysis of the findings revealed that the PHAs and APHAs experienced shunning, ostracization, labeling, and disempowering practices when accessing health care services. The conceptual analysis of the data was carried out iteratively with a process of theorizing, as described by Morse (1994). Theorizing refers to the process of interpreting the data in the context of relevant theory, and involves the "systematic selection and fitting of alternative models to the data" (Morse, p. 33). Based on our theorizing, we argue that the experiences and practices encountered by participants when accessing health services are mechanisms for social control. In this article, illustrative quotes (using pseudonyms, and with references to sites and place names removed) are used to highlight the social control mechanisms.

\section{Findings}

Thirty-three HIV-positive individuals (16 aboriginal and 17 nonaboriginal) participated in an in-depth interview. The aboriginal identity of the APHAs included First Nations (10), Métis (3), Inuit (2), and unknown (1). Twenty-two men, 9 women, and 2 transgender individuals participated, and 
ranged in age from 31 to 56 years (mean 40.6 years). The primary modes of HIV transmission for the sample were injection drug use (IDU; $n=17$ ) and men who had sex with men $(n=16)$. Twenty-seven HCPs, including physicians, nurses, social workers, psychologists, and a dentist participated in an in-depth interview (20) or a focus group (7). Three of the HCPs were men and 24 were women; 2 of the 27 HCPs were aboriginal. All of the HCPs had experience in acute care or community settings, and explained that a personal connection to the area of HIV and AIDS was a reason for their current work involvement. Several HCPs reported that their initial experience in HIV began through student practical placements or professional training placements.

All of the interviews and focus groups were conducted in English over a 1-year period of time and took place in one of the participating organizations. The interviews lasted approximately 1 hour, whereas the focus groups lasted approximately 2 hours. Participants described their experiences of stigma and stigmatizing practices in a variety of social situations involving family members, friends, and coworkers, and in interaction within social institutions including health care settings, prisons, shelters, and workplaces. HCPs described stigmatizing practices in the health care institutions where they worked, and to a lesser extent in other health care institutions providing services for their clients. The specific social control mechanism that was introduced through a particular institutional policy was often coupled with other factors that worsened clients' experiences of stigma. Social and institutional controls were encountered by APHAs and PHAs on a regular basis, taking both positive and negative, and overt and covert forms. Although both nonaboriginal and aboriginal participants employed a variety of strategies to manage stigma, aboriginal participants used additional cultural approaches (e.g., connecting with elders, participating in ceremonies) to mitigate the negative impacts of stigma. These approaches in turn influenced the uptake of "healthy" coping strategies (e.g., establishing and rebuilding trust in HCPs and health care organizations). Although an important finding, the focus of our analysis for this article was not a comparison of aboriginal and nonaboriginal experiences related to social control; the experiences of aboriginal participants will be discussed in greater detail in a forthcoming article.

\section{Exerting Social Control}

Shunning and ostracization. Shunning and ostracization were commonly cited social control mechanisms that were both intentional and unintentional. These controls occurred in many settings and with many individuals, ranging from family members to HCPs and prison workers.
For example, several of the participants noticed changes in how they were treated at work, and/or in what their responsibilities were following disclosure of their HIV status. Kory was no longer allowed to assist with the preparation of food:

I was working part time when I first found out. I was helpin' out at an AA [Alcoholics Anonymous] club and I noticed, because my boss didn't want the older members to find out, my duties in the kitchen got cut: there was no more cooking. They were scared in case I cut myself and stuff like this.

Quinn, on the other hand, was required to wear additional "protective" clothing that made him feel ostracized by other staff:

They made me wear gloves. I mean the other staff I saw they would do that. They wouldn't wear hairnets, stuff like. And they made me dress up like some sort of space person [laugh]. Because they thought, "Oh this person!" I just felt very ostracized.

The shunning and ostracization that PHAs and APHAs experienced were intricately linked with shunning because of other characteristics. Most participants experienced a layering, or a double (or triple) burden of stigma because they had become infected through a behavior that was highly stigmatized (e.g. IDU, commercial sex work); belonged to a culture (aboriginal), gender (women), or social class (poor, prisoner) that was vulnerable to stigmatization; or suffered from another illness (e.g., mental illness) that was stigmatized. Feeling shunned because of sexual orientation was described by several participants, particularly gay men. Some participants, therefore, chose to keep their sexual orientation and their HIV diagnosis secret because of a fear of being shunned by family, friends, and HCPs:

There's a lot of AIDS jokes and gay jokes, and hatred and bigotry, so it's better to keep it hidden and keep it to yourself and then you won't get picked on, or ostracized, or shunned. You could get shunned or ostracized very quickly by a group of people, and then sit around and watch who comes to socialize with you.

Several of the participants commented on the layered stigma they endured as aboriginal, HIV-positive individuals. Nolan referred to this as "the stigma within the stigma," and recalled being labeled as "another drunken Indian ... a faggot drunken Indian." Fred was also aware 
of having experienced layered stigma. He recalled that "it was really kind of like a black labeling. I just didn't want to be put in that category [HIV] because I was already dealing with a lot of others issues, one being Native, two being in jail." One of the HCPs provided strong evidence of institutional shunning, especially in facilities that did not routinely see clients with HIV:

If they go to a facility or place that doesn't routinely provide care to HIV-positive people, then it's like there is this level of discomfort that the staff have 'cause they don't do it on a day-to-day basis, so they don't think about how their behavior might make a person feel.

Kelly was not prepared to disclose her HIV status when she was in prison because of the shunning she had observed toward others:

I wasn't ready to address my HIV because of the simple fact that I'd seen other girls in the system [prison] being shunned from having friends and going out and doing things, and it was awful. And I knew I had this deep little dark secret behind me that I was sick.

Shunning carried a high risk for HIV-positive individuals because it could result in limited social support, highly vulnerable living situations, and lack of access to required care, ultimately making it more difficult for participants to manage their illness.

Labeling. Labeling was also a fairly common practice that marginalized persons living with HIV. At the time of the interview, Ethen was no longer using cocaine; however, he was still being treated as an addict by HCPs. This influenced the care he received, particularly in relation to pain relief:

I find the medical profession treats me [first] like an addict, and then like a patient. "Okay, you're an addict, so we're not going to prescribe anything to you that's a narcotic." It's very frustrating. Yes, I was an addict. No, I'm not an addict anymore. Yes, I do have legitimate pain.

Labeling occurred when clients presented with comorbidities or had complications arising from AIDS. When hospitalized for pneumonia, Kelly felt that the color of the gown that she was given labeled her as being infectious:

At one time, because I had such a bad cough, they put me in a yellow gown and I guess that yellow gown means I was in a certain kind of room all by myself [laughs]. I didn't like that treatment, because I felt like I had [laughs] something that nobody else had in the whole hospital. I just felt like nobody would come near me. And then they found out that I didn't have TB, so then they put me in a different gown and I could leave my door open.

Aaron recalled being labeled by a nurse who assumed that his HIV status was synonymous with being gay:

I have Kaposi's [sarcoma] on my left foot, on my large toe, and Kaposi's- it looks like a big, black bruise - and so she [nurse] asked me what it was and I explained it to her, and she said, "Why are your toenails painted?" And I looked at her and I said, "Well, they're not. That's part of the illness." And she said, "What?" And I explained to her, I said, "Well," and I kept my voice down, and I said, "Well, I'm HIV positive," and she walked out to another nurse and she said, "Why didn't you tell me there's a fag in there that has AIDS?"

Participants described situations when their HIVpositive status labeled them. For example, Dennis had the following experience when he was in prison:

They had a like a day timer board [clip board] on the table, and if you looked at it you could see everybody's name and assigned cell. Well, above the ones that were positive they had "HIV positive" written. You know? Hell!

In some health care settings, "caution sheets" were placed on patient's charts to alert HCPs that a patient was HIV positive. Charles, a physician, believed that caution sheets contributed to stigma and were not necessary:

It contributes to the stigma and fear piece. Like, all of a sudden there's this glaring caution sheet as soon as you flip the chart, and you go, "Oh, caution. What should I be looking out for?" Usually, they're used for allergies, sensitivities, or then you look down and see they're HIV. To me, it's a question of, why does this need to be on the front of the chart?

A few participants recalled feeling comfortable in settings that did not "label" them. Cecil found it very comfortable at one AIDS service organization: "I like it here. It's nice. I mean, you feel kind of safe, you know, it'speople know what you've got. Nobody attaches, puts a sign on your back. It feels comfortable; a comfortable feeling around here." 
Participants were very sensitive about receiving special privileges or accessing services that would identify them as HIV positive. Several felt uncomfortable receiving special foods or additional food when in a shelter or prison. This practice could identify them as being HIV positive and put them at risk of being ostracized:

You don't get support in jail as far as I'm concerned. If you're HIV [positive] you get a double meal as soon as you walk into the jail. They say, "Are you on a diet or a special diet?" And if you say yes, then everybody knows on an arranged diet you're HIV positive.

Explicit signage on HIV clinics made it awkward to enter or approach the site for some participants, whereas others experienced no difficulty. Dennis had concerns that his diagnosis became public when he accessed an HIV clinic:

Having this sign glowing at the top of our building is appalling to me. I don't think that we need to put "HIV" up at the front of our building. We don't need that. People need to be able to come in and out of here without that stigma being attached to them.

\section{Disempowering Health Care Practices}

Social control was also exerted through disempowering health care practices. Several of the participants spoke of situations in which they were excluded, directly or indirectly, from the decision making about their life choices or their health care. This practice compromised the trust that PHAs and APHAs had in their HCPs, and resulted in feelings of disempowerment. Participants shared stories of HCPs who did not ask for consent to carry out an HIV test; judged clients based on their physical appearance, HIV or Hepatitis C status; made assumptions about who to share the client's HIV status with; pressured them to change their lifestyle; or used universal precautions inappropriately. Alfred was not consulted by his physician prior to having an HIV test:

They tested me for everything. But they never asked me if I wanted an HIV test. I was really sick, and I've never been that sick before in my life. So, uh, they did the HIV test, I guess, at one point or another.

One HCP reported that in her experience, if a patient did not give consent for an HIV test, it would often be done anyway on previously collected blood:
Well, then it goes above their head, kind of thing, 'cause it has to be done. It's consent if, we prefer you to say yes, [laughs]. Then we have to go through other channels, yeah, because we probably already have some blood of yours anyways. So even if they refuse to let us poke again, there's something up in the lab.

Another HCP noted that pregnant women were often not asked for consent to be tested for HIV, a practice that contradicts Canadian standards for informed consent: "When they find out you're pregnant, automatically would do an HIV test. They actually are supposed to ask consent; the thing is they usually don't. The test is just done. And that's very bad, because there's no pretest counseling."

Some participants did not believe that they were equal partners in decisions about their health, or were judged based on their appearance when accessing health services. Jenny was very resentful of the approach used by some HCPs to try to convince her to give up her use of intravenous drugs. She recalled feeling pressured by a nurse:

To give up my sets, my needles, and all the time I said, "Listen, you can sit here and preach to me until you're black and blue in the face, but I'm not ready. I'll tell you that right now. I am not willing to give up the needle. And nobody can make that decision except me." I said, "I'm in control of it, and I'm not ready to quit, so don't even come tell me." And the nurse, like, and one of these type people, trying to help people, and get them clean and straight and all this fuckin' bullshit.

Despite the pressure, Jenny felt that she needed to maintain control of the decision to quit drugs. Oliver had not been consulted prior to the physician telling his sister that he was HIV positive. After learning about Oliver's HIV status, his sister told many others:

Another doctor had accidentally told her [sister] about me, and I thought, "What are you telling her this for?" And he [doctor] said, "Well, she's your sister. Aren't you close?" And I said, "Not at all! I don't trust her. If there's anybody on this planet I wouldn't tell, it's her! Now everybody is gonna know! She's already blabbed vital information about me."

Some PHAs and APHAs described feeling judged when they accessed care, based on their appearance. Bob tried to minimize discrimination when he accessed health services by taking great care with his appearance: 
Because I was so anxious to avoid it [stigma], I would be dropping in, in a shirt and tie, relatively presentable, and I think that in itself might make it a little bit different than somebody who has, you know, come from the street. I think still for most of us one's appearance makes a big difference. And so perhaps that might be another reason why I might have been fortunate there.

The inappropriate use of universal precautions was an institutional control that isolated and disempowered individuals living with HIV. For example Ethen, a PHA, experienced differences in the approach to universal precautions depending on where he accessed health services. He recalled visiting a small town for the treatment of a lung infection: "I had better care there than I ever received in the city. There was no freaking out. There was none of this, 'Quick, get [the] gloves."' Wilma, a community development worker, commented that nurses had used excessive infection control precautions when her friend's HIV-positive brother had gone to a major hospital for treatment:

The nurses were standing there, and they had this disgusting look on their face, and gloving up, and gowning up and everything, masking up. I'm sure if they could have gone in there with some kind of space suit, they probably would have. So you kind of wonder what happened to those people and compassion.

Jon recalled troubling situations when excessive universal precautions were used with friends:

I know a lot of people who have come in, or gone home to visit family and gotten sick, and had to go to the emergency [department] in their local town, and all of a sudden they find out they're positive, they're almost like pariahs. They [health care workers] triple glove themselves. And they do this in front of the people. And these are professionals.

\section{Managing, Resisting, and Mitigating Social Control}

Efforts to manage, resist, and mitigate social control mechanisms were described by participants. PHAs and APHAs often forgave stigmatizing behaviors, and carefully considered to whom they disclosed their HIV status and exactly what to disclose. The practice of universal precautions and the ability to bend the rules and shift the services were considered essential to the provision of respectful, nondiscriminatory care. Strategies to reduce labeling were also important.
Forgiving behavior. Almost half of the participants provided justification for the shunning and stigmatizing behaviors they encountered. They understood and even forgave these behaviors for a variety of reasons: it was natural for individuals to be nervous about HIV because of its infectivity; it might be the HCPs' first experience with HIV; it was a new disease; or the HCP was not ready to care for a person living with HIV:

She was just a walk-in clinic type doctor. And new, young, family oriented. And I think she had her strong suspicions of my sexuality, and that plus my new diagnosis. No. She wasn't ready, which was fair of her, but I felt discriminated against a bit. I was hurt a little bit.

In some instances, participants made no attempt to correct discriminatory practices because they felt it might be difficult for the HCP to manage their care. Participants not only had to deal with a stigmatizing practice from an HCP, but were up against a set of well-entrenched stigmatizing institutional practices.

Balancing disclosure. Participants described various permutations of disclosure, sometimes in collusion with HCPs, as a means to manage stigma. For example, some participants disclosed their hepatitis $\mathrm{C}$ but not their HIV status to ensure the use of universal precautions, and at the same time decrease the likelihood of stigma:

He [doctor] told me if I ever go to the hospital or anything else just tell them I have hepatitis $\mathrm{C}$, do not tell them I have HIV. But then when I tell them I have HIV they completely turn; they're not the same kind of people. They don't even want to touch you.

Participants described disclosing their HIV status to family and friends using approaches to normalize the diagnosis. Dennis was able to "slide" his HIV diagnosis into the conversation:

To me it wasn't a big deal. Nine years of living with someone that already had it, it wasn't, you know, new news to anybody about, you know, what it is or how it's spread. They were all educated by then, so it was quite easy for me to just sort of slide it in there and, you know, just go about things.

Practicing universal precautions. The consistent use of universal precautions was seen by PHAs, APHAs, and most HCPs as a key factor to mitigate stigma. They believed that if universal precautions were used with all patients, the use of protective apparel would not identify them as HIV positive. Despite this finding, participants described situations when their medical record clearly identified 
them as HIV positive, yet HCPs failed to use universal precautions. Kory, a PHA, felt chastised when a nurse did not use gloves: "She put an IV or something in me without gloves, and she flipped. That hurt because I felt like I did something wrong, but it's all over my file, like I don't hide it." The selective use of gloves by HCPs was seen as stigmatizing, and at the same time the lack of gloves was viewed as poor practice because of the risk of infection to both the patient and the HCP. It was not helpful when HCPs failed to use universal precautions in an attempt to demonstrate their comfort with persons living with HIV and AIDS. Carmen commented on the challenges she had experienced in deciding when to wear gloves:

Like, if you're not wearing gloves before you go in to see someone, and someone sees you, you're often, like, "What are you doing? Put your gloves on." We don't go in and chart, do vitals with gloves on, necessarily, 'cause I find that very impersonal, and people-stand-offish. You know, like, "What does she think I have?" Like, "Oh, my God, what's wrong with me?"

Bending the rules. Several of the HCPs spoke about the need to "bend the rules" when providing care to persons living with HIV. Charles commented that his organization bent the rules to enhance access:

Officially, you cannot participate in a program or you can't even attend that program if you're intoxicated, so that's been a bit of an issue for me. Therefore, that strict policy piece is being relaxed; we're bending the rules a little bit.

Although caregivers provided a number of examples of how they relaxed institutional policies in an effort to create a less-stigmatizing environment, clients still perceived this as controlling behavior on the part of the caregiver. It was usually the caregiver and not the client who made the decision about whether or not to relax policies. One HCP stated that his approach to care emphasized working with the client based on the client's life and circumstances at the time. He encouraged clients to express their preference regarding HIV testing:

I make it a policy of never trying to tip the balance one way or another in pushing someone one way or another to either decide to get tested or not to get tested. So it would be them talking their way to that on their own.

Shifting services. Health care providers commented on the necessity to expand and shift services for persons living with HIV to ensure that clients' needs were met and care was continuous. Several HCPs commented on the growth and evolution that had taken place within the organizations they worked in:

As we've grown as an organization, and as we've become stable, there've been changes in the clinic. Yeah, I'd say it's more evolved from a nurse practitioner point of view. We've tried to institute changes that lead to more continuity of care, so that's one way. And we've tried to sort of work at becoming more of a team, so the communication between providers I think has probably increased.

Sandra described her organization's multidisciplinary approach to patient care, and her efforts to provide clientcentered care to establish trust:

We're all committed to the clients. We kind of decided that it would work out better if I went to see them. And then with the street clients, when I first started, I knew that a large percentage of our clientele were street people, and they don't like coming to the hospital; they've had bad experiences in the hospital. And I started these [outreach groups in inner city agencies] shortly after I started here. And that was to be where the street people are so that they can get to know me in their environment, and it worked! It worked.

Our document review revealed that institutional policies and procedures did not overtly encourage stigmatization; however, HCPs used discretionary practices in an attempt to mitigate stigma. Within the larger social context, HIV disease was still stigmatized. Therefore, even when organizations and HCPs attempted to put destigmatizing practices in place, they could inadvertently become stigmatizing within the larger social or health care system.

Reducing labeling. The ability to access HIV care services without being labeled as HIV positive was seen to be very important from the perspective of the HCPs. Various institutional efforts were made to try and reduce the likelihood of labeling. For example, a variety of services were provided in the same setting:

When we ask them [clients] to give us a couple of snapshots of what they thought of our service, they always tell us they like the fact that no one can label them as having HIV just because they've seen them here. A lot of them wouldn't come in if seeing them here would mean that everyone else that saw them here would know they had HIV.

Clients were often aware of ways in which they might report stigmatizing experiences in the health care setting; 
however, they often decided not to report stigmatizing experiences because this might jeopardize their relationship with the HCP.

\section{Discussion}

Our findings from the current study document the use of stigmatization as an institutional and social control mechanism that contributes to the marginalization of persons living with HIV and AIDS. The experiences of PHAs and APHAs provide exemplars of social control mechanisms that were sometimes explicit, and other times subtle. When viewed in their entirety, the findings provide a potent illustration of the inequitable power differentials and social control mechanisms referred to by Parker and Aggleton (2003) in their conceptualization of stigma. Conceptualizations of stigma must also account for the human capacity for agency, and allow for the possibility of resistance and change (Campbell \& Deacon, 2006; Howarth, 2006). Our findings support this dimension of stigma theory by highlighting strategies that both persons living with HIV, and those providing care for them, employed to manage, resist, and mitigate social control mechanisms, thereby attempting to reduce stigma.

The labeling associated with the diagnosis of HIV or AIDS serves as a social control mechanism to distance the infected from the uninfected. Mawar and colleagues (2005) argued that labels such as "risk group" and the "general public" help to distance "them" [the infected] from "us" [the uninfected]. Similarly, Sontag (2001) argued that an HIV positive diagnosis "separates the sick from the well" (p. 116) and labels the individual as "seemingly healthy but doomed" (p. 119). Scott (2009), in interpreting the illness meanings of AIDS, described it as "deeply discrediting [and] ... a visible state that marks physical failure, moral failure, and social ostracism" (p. 464). The themes of shunning and labeling highlighted in the current study are comparable to some of the constructs identified by researchers for the measurement of stigma. An Internalized AIDS-Related Stigma Scale developed by Kalichman and colleagues (2009) included items to measure the endorsement of social sanctions (e.g., restriction on freedom and isolation) toward persons living with HIV. The AIDS Stigma Scale developed by Berger, Ferrans, and Lashley (2001) included the factor "concern with public attitudes about people with HIV" as one of four factors in the scale. Similarly, an AIDS stigma instrument developed in five African countries by Holzemer, Uys, Chirwa, and colleagues (2007) included social isolation and verbal abuse as factors in the stigma measure. The overlap of themes in our qualitative findings with the constructs in the scales developed to measure stigma suggest that our findings are robust.
The layering of AIDS stigma described by participants in our study has been reported previously in the literature (Reidpath \& Chan, 2005; Ware, Wyatt, \& Tugenberg, 2006) in relation to poverty (Masanjala, 2007), homosexuality (Dodds, 2006), gender (Mill, 2003), and ethnicity (Mill et al., 2009). Despite recognition of this phenomenon, there is a paucity of tools to measure layered stigma, and limited reports of the measurement of stigma simultaneously across several levels, and in particular the population level (Nyblade, 2006). Campbell and Deacon (2006) argued that the overlapping nature of stigma for some individuals and groups makes it more difficult to exercise agency and resistance, and necessitates the assistance of external agents to resist stigma.

As a process, stigmatization is "linked to competition for power and the legitimization of social hierarchy and inequality" (Parker \& Aggleton, 2003, p. 18). Participants in the current study described disempowering health care practices when accessing health services. Power within the health care encounter generally, and with persons living with HIV specifically, can be an important social control mechanism. The dominant and powerful role of HCPs (in particular physicians) in the HIV testing experience (Worthington \& Myers, 2003) and the treatment decisions of persons living with HIV (Taylor, 2001) have been documented in previous research. Taylor argued that the medical surveillance of an individual following an HIV-positive diagnosis is a "manifestation of paternalistic power in the guise of knowledge-seeking and in the name of beneficence" (p. 794). Worthington and Myers reported that for some HIV test recipients, anxiety was based on feelings of powerless and lack of control in negotiating the test experience. Health care providers also exert power in their role as gatekeepers to the health care system (Freund \& McGuire, 1998).

Our findings suggest that stigma is primarily a mechanism for social control; however, institutional responses to stigma might have positive outcomes for some marginalized communities by promoting empowerment and political activism (Cornish, 2006; Gilmore \& Somerville, 1994), thereby mitigating inequities. Institutions might create an environment that promotes stigmatization, but they might also "open up spaces for resistance and social change" (Campbell \& Deacon, 2006, p. 414). Deacon (2006) cautioned that to ensure that both negative and positive responses to stigmatization are explored, stigma should not be defined in terms of discrimination. The tendency to conflate the two terms has resulted in a lack of analytical clarity of the concept of stigma. Our analysis of the use of stigma as a social control mechanism with persons living with HIV provides greater clarity to the phenomenon of stigma. 
Stigma plays a role in maintaining the status quo and balancing the social order. Campbell, Foulis, Maimane, and Sibiya maintained that stigma is a form of "social psychological policing" (2005, p. 808) that punishes persons who challenge unequal power relations of gender, generation, and ethnicity. Parker and Aggleton argued that "to untie the threads of stigmatization and discrimination that bind those who are subjected to it is to call into question the very structures of equality and inequality in any social setting" (2003, p. 18). Similarly, Campbell and Deacon (2006) pointed out that the nonstigmatized have a significant investment in maintaining the status quo because of the psychological and social benefits associated with "othering." As a consequence, interventions to mitigate the impact of stigma are likely to prove challenging to implement.

The use of excessive or inconsistent infection control measures reported by participants has also been reported among African, HIV-positive migrants to England (Dodds, 2006). In the current study, HCPs continuously assessed and redefined the practices and procedures that were in place to protect the public, while at the same time trying to provide an environment that was safe for the client and conducive to nondiscriminatory care. Health care providers found themselves at the interface between the interests of clients and the interests of public health. They attempted to build positive relationships as a means of bringing compassion to their work, despite the necessity of abiding by institutional infection control mechanisms such as universal precautions. In essence, the relationship with their clients was used as a means to offset institutional social control mechanisms. The dilemma described by HCPs about when to use gloves highlights the tensions they experienced in balancing the rights of the individual living with HIV with the rights of the larger public. This tension was identified early in the epidemic (Bayer, 1989), and has been recently framed as a human rights issue (Mawar et al., 2005). Health care providers must balance the provision of humanistic, compassionate care with their professional responsibility to ensure the health of the public. To negotiate this balance, structural changes are required within institutions to enable HCPs to engage with clients in meaningful relationships.

Clients balanced the risk of social shunning as a result of disclosure with their desire for good care. In managing their illness, PHAs and APHAs interfaced with many levels of organizations and society, levels at which the experience of stigma was constantly shifting. They described the tensions experienced when using secrecy as a means to protect themselves from stigma. The need to balance secrecy with the necessity to disclose has been described by persons living with HIV in previous research (Dodds, 2006; Greeff et al., 2009; Mill, 2003). Occasionally participants lost control over the decision to disclose when HCPs disclosed their status without their permission. This has been referred to as "mismanaged disclosure" (Sandelowski, Lambe, \& Barroso, 2004, p. 127).

Persons living with HIV and AIDS attempted to take control of their respective situation as a strategy to manage stigma. The process of balancing decisions about disclosure with the need for secrecy is an example of PHAs exerting social control. Joachim and Acorn (2000a) referred to this phenomenon as protective disclosure, and suggested that it is typically planned. The process of taking control is similar to the process of normalization that Joachim and Acorn (2000b) described in relation to living with chronic illness. Normalization involves managing or adapting to a chronic illness. These authors argued that to understand the complexity of a chronic illness, it is important to view the illness not only through a stigma lens, but also through a normalization lens.

The evolution of AIDS service organizations and the need for knowledgeable care, treatment, and support for persons living with HIV have created an institutionalized health care delivery system that might have inadvertently fueled stigmatization and created inequitable programs. The development of AIDS-specific programs, policies, and organizations, referred to as AIDS exceptionalism, can be traced to the early years of the AIDS epidemic and fear of the public health implications of AIDS. Whereas AIDS exceptionalism might have been an appropriate response to the emergence of HIV and AIDS, as the epidemic has progressed it has become increasingly difficult to defend the need for a policy response that is fundamentally different than the response to other infectious diseases (Bayer, 1991). Some authors have argued that AIDS exceptionalism should be challenged on the basis that it is unjust (Casarett \& Lantos, 1998) and creates ethical issues related to access (Bayer, 1999). AIDS-specific services provide highly specialized and state-of-the-art services; however, the clients are labeled as soon as they walk through the door, contributing to the likelihood of stigmatization. Furthermore, the need for highly specialized knowledge for the management of AIDS leads to a wider gap between the specialist and the layperson (Freund \& McGuire, 1998), the powerful and the powerless.

\section{Implications for Practice, Policy, and Research}

Our findings illustrate the urgent need for the development and implementation of interventions that manage, resist, or mitigate AIDS stigma and enhance health equity. Several authors (Campbell \& Deacon, 2006; Campbell et al., 2007) have advocated multilevel interventions to address AIDS stigma. Campbell and colleagues (2007) 
stressed the importance of complementary "top-down" and "bottom-up" interventions to address AIDS stigma, and the provision of "social space" for communities to critically examine issues related to HIV and AIDS. The realization that stigma is determined by a complex set of interrelated factors (e.g., individual, community, and political) results in the need for multilevel and multistrategy intervention programs (Edwards, Mill, \& Kothari, 2004) across sectors.

In consideration of Parker and Aggleton's (2003) perspectives on social control mechanisms and power, HCPs and institutions must question whether a given policy related to HIV disclosure would yield the same type and level of control for clients who are marginalized vs. those who are not. In addition, the underlying social inequalities experienced by clients with HIV, and in particular those with layered stigma and those who have experienced social oppression, must be considered when identifying means to operationalize institutional HIV and AIDS policies. Our findings suggest that because stigma occurs within a social context where social control mechanisms are in place, there are no stigma-free policies and procedures. Policymakers must ask whether a policy potentially produces or reproduces social inequalities (Parker \& Aggleton), and what social order is maintained or modified as a result of a particular policy. This needs to be considered in relation not only to the client's experiences of inequity in the health care organization, but also to his or her wider social and work experience.

Our study findings suggest a number of propositions that require more exploration. Research is needed to examine the ways in which given policies such as universal precautions for HIV and AIDS exert social control and create inequities. The sources of power and the struggles for power that are part of social control mechanisms require additional elaboration. Various power hierarchies need to be considered here: those operational within the health care and social services institutions and within and between professional groups, and those operational within social structures. Research is also required to understand the intersection of societal attitudes, institutional structures, and individual experiences, including comparisons of the experiences of PHAs and APHAs. More historical and chronological information is needed to explore how social control mechanisms develop and how flexible or intransigent they might be to shifting social views. Finally, institutional ethnographies and embedded case studies might be useful methodologies to expose the inequities that contribute to the stigma experience and to explore layered stigma.

\section{Conclusion}

Our study contributes to an expanded theory of stigma and stigmatization as interrelated individual, social, and institutional processes. It might be difficult for PHAs and APHAs to resist and challenge the social control mechanisms that reproduce stigma. To do so might limit their access to health care services. To do so might increase their vulnerability with respect to social support from family and HCPs. To do so might reduce the availability of treatment options. And to do so might fuel the flames of discrimination and magnify the experience of stigma. Resistance is much more than questioning a stigmatizing practice; it is questioning a much larger social order that creates inequities and crosses professions, institutions, and society at large.

\section{Acknowledgments}

We extend our thanks to the participants living with HIV and AIDS for their willingness to share very personal aspects of their lives. In addition, we thank the health care providers who took time from their busy schedules to share their perspectives on the topic.

\section{Declaration of Conflicting Interests}

The authors declared no conflicts of interest with respect to authorship and/or publication of this article.

\section{Funding}

The authors disclosed receipt of the following financial support for the research and/or authorship of this article: Funding was received from the Canadian Institutes for Health Research.

\section{References}

Adelson, N. (2005). The embodiment of inequity: Health disparities in aboriginal Canada. Canadian Journal of Public Health, 96, S45-S62. Retrieved from http://pubs.cpha.ca/ PDF/P24/22247.pdf

Aikins, A. D. (2006). Reframing applied disease stigma research: A multilevel analysis of diabetes stigma in Ghana. Journal of Community \& Applied Social Psychology, 16(6), 426-441. doi:10.1002/casp.892

Alonzo, A. A., \& Reynolds, N. R. (1995). Stigma, HIV and AIDS: An exploration and elaboration of a stigma trajectory. Social Science \& Medicine, 41(3), 303-315. doi:10.1016/ 0277-9536(94)00384-6

Battiste, M., \& Henderson, J. Y. (2000). Protecting indigenous knowledge and heritage. Saskatoon, SK, Canada: Purich.

Bayer, R. (1989). Private acts: Social consequences. New York: Macmillan.

Bayer, R. (1991). Public health policy and the AIDS epidemic. An end to HIV exceptionalism? New England Journal of Medicine, 324(21), 1500-1504. Retrieved from http://content .nejm.org/cgi/content/brief/324/21/1500

Bayer, R. (1999). Clinical progress and the future of HIV exceptionalism. Archives of Internal Medicine, 159(10), 1042-1048. Retrieved from http://archinte.ama-assn.org/cgi/ reprint/159/10/1042 
Berger, B. E., Ferrans, C. E., \& Lashley, F. R. (2001). Measuring stigma in people with HIV: Psychometric assessment of the HIV stigma scale. Research in Nursing \& Health, 24(6), 518-529. doi:10.1002/nur.10011

Boulos, D., Yan, P., Schanzer, D., Remis, R. S., \& Archibald, C. (2006). Estimates of HIV prevalence and incidence in Canada, 2005. Canada Communicable Disease Report, 32(15), 165-174. Retrieved from http://www.atlantic.phac-aspc.gc.ca/publicat/ ccdr-rmtc/06pdf/cdr3215.pdf

Brandt, A. M. (1987). No magic bullet: A social history of venereal disease in the United States since 1880. New York: Oxford University.

Campbell, C., \& Deacon, H. (2006). Unraveling the contexts of stigma: From internalization to resistance to change. Journal of Community \& Applied Social Psychology, 16(6), 411-417. doi:10.1002/casp.901

Campbell, C., Foulis, C. A., Maimane, S., \& Sibiya, Z. (2005). "I have an evil child at my house": Stigma and HIV/AIDS management in a South African community. American Journal of Public Health, 95(5), 808-815. doi:10.2105/ AJPH.2003.037499

Campbell, C., Nair, Y., Maimane, S., \& Nicholson, J. (2007). 'Dying twice': A multilevel model of the roots of AIDS stigma in two South African communities. Journal of Health Psychology, 12(3), 403-416. doi:10.1177/1359105307076229

Casarett, D. J., \& Lantos, J. D. (1998). Have we treated AIDS too well? Rationing and the future of AIDS exceptionalism. Annals of Internal Medicine, 128(9), 756-759. Retrieved from http://www.annals.org/content/128/9/756.abstract

Cornish, F. (2006). Challenging the stigma of sex work in India: Material context and symbolic change. Journal of Community \& Applied Social Psychology, 16(6), 462-471. doi:10.1002/casp.894

Das, V. (2001). Stigma, contagion, defect: Issues in the anthropology of public health. Retrieved from http://www.stigma conference.nih.gov/DasPaper.htm

Deacon, H. (2006). Towards a sustainable theory of healthrelated stigma: Lessons from the HIV/AIDS literature. Journal of Community \& Applied Social Psychology, 16(6), 418-425. doi:10.1002/casp.900

Des Jarlais, D. C., Galea, S., Tracy, M., Tross, S., \& Vlahov, D. (2006). Stigmatization of newly emerging infectious diseases: AIDS and SARS. American Journal of Public Health, 96(3), 561-567. doi:10.2105/AJPH.2004.054742

Dodds, C. (2006). HIV-related stigma in England: Experiences of gay men and heterosexual African migrants living with HIV. Journal of Community \& Applied Social Psychology, 16(6), 472-480. doi:10.1002/casp. 895

Duffy, L. (2005). Suffering, shame, and silence: The stigma of HIV/AIDS. Journal of the Association of Nurses in AIDS Care, 16(1), 13-20. doi:10.1016/j.jana.2004.11.002

Edwards, N., Mill, J. E., \& Kothari, A. R. (2004). Multiple intervention research programs in community health. Canadian Journal of Nursing Research, 36(1), 41-54. Retrieved from http://www.ingentaconnect.com/content/mcgill/cjnr/2004/ 00000036/00000001/art00005

Ermine, W., Sinclair, R., \& Jeffrey, B. (2004). The ethics of research involving indigenous peoples. Report of the indigenous peoples' health research centre to interagency advisory panel on research ethics. Saskatoon, SK, Canada: Indigenous Peoples' Health Research Centre.

Fee, E., \& Parry, M. (2008). Jonathan Mann, HIV/AIDS, and human rights. Journal of Public Health Policy, 29(1), 54-71. doi:10.1057/palgrave.jphp.3200160

Freund, P. E. S., \& McGuire, M. B. (1998). Health, illness and the social body: A critical sociology. Upper Saddle River, NJ: Prentice Hall.

Gilmore, N., \& Somerville, M. A. (1994). Stigmatization, scapegoating and discrimination in sexually transmitted diseases: Overcoming 'them' and 'us.' Social Science \& Medicine, 39(9), 1339-1358. doi:10.1016/0277-9536(94)90365-4

Goffman, E. (1963). Stigma: Notes on the management of spoiled identity. Englewood Cliffs, NJ: Prentice-Hall.

Gracey, M., \& King, M. (2009). Indigenous health part 1: Determinants and disease patterns. Lancet, 374, 65-75. doi:10.1016/S0140-6736(09)60914-4

Greeff, M., Phetlhu, R., Makoae,L. N., Dlamini, P. S.,Holzemer, W. L., Naidoo, J. R., . . Chirwa, M. L. (2009). Disclosure of HIV status: Experiences and perceptions of persons living with HIV/AIDS and nurses involved in their care. Qualitative Health Research, 18, 311-324. doi:10.1177/ 1049732307311118

Grove, K. A., \& Kelly, D. P. (1997). 'But nice girls don't get it!': Women, symbolic capital, and the social construction of AIDS. Journal of Contemporary Ethnography, 26(3), 317-338. doi:10.1177/089124197026003003

Gupta, G. R., Parkhurst, J. O., Ogden, J. A., Aggleton, P., \& Mahal, A. (2008). Structural approaches to HIV prevention. Lancet, 372(9640), 764-775. doi:10.1016/S0140-6736(08)60887-9

Hawkins, T. (2006). Appearance related side effects of HIV-1 treatment. AIDS Patient Care \& STDS, 20(1), 6-18. doi:10.1089/ apc.2006.20.6

Holzemer, W. L., Uys, L., Makoae, L., Stewart, A., Phetlhu, R., Dlamini, P. S., ... Naidoo, J. R. (2007). A conceptual model of HIV/AIDS stigma from five African countries. Journal of Advanced Nursing, 58(6), 541-551. doi:10.1111/j.1365-2648 .2007.04244.x

Holzemer, W. L., Uys, L. R., Chirwa, M. L., Greeff, M., Makoae, L. N., Kohi, T. W., . . Naidoo, J. R. (2007). Validation of the HIV/AIDS stigma instrument-PLWA (HASI-P). AIDS Care, 19(8), 1002-1012. doi:10.1080/09540120701245999

Howarth, C. (2006). Race as stigma: Positioning the stigmatized as agents, not objects. Journal of Community \& Applied Social Psychology, 16(6), 442-451. doi:10.1002/casp.898

International Federation of Red Cross and Red Crescent Societies. (2004). Renewing our voice: Code of good practice for NGOs responding to HIV/AIDS. Geneva, Switzerland: Author. 
Joachim, G., \& Acorn, S. (2000a). Stigma of visible and invisible chronic conditions. Journal of Advanced Nursing, 32(1), 243-248.

Joachim, G., \& Acorn, S. (2000b). Living with chronic illness: The interface of stigma and normalization. Canadian Journal of Nursing Research, 32(3), 37-48. Retrieved from http:// www.ncbi.nlm.nih.gov/pubmed/11928132

Kalichman, S. C., Simbayi, L. C., Cloete, A., Mthembu, P. P., Mkhonta, R. N., \& Ginindza, T. (2009). Measuring AIDS stigmas in people living with HIV/AIDS: The internalized AIDS-related stigma scale. AIDS Care, 21(1), 87-93. doi:10.1080/09540120802032627

Kaufert, J., Commanda, L., Elias, B., Grey, R., Masuzumi, B., \& Young, K. (2001). Community participation in health research ethics. In J. Oakes, R. Riewe, M. Bennett, \& B. Chisholm (Eds.), Pushing the margins: Native and northern studies (pp. 50-61). Winnipeg, Canada: Native Studies Press.

King, M., Smith, A., \& Gracey, M. (2009). Indigenous health part 2: The underlying causes of the health gap. Lancet, 374, 76-85. doi:10.1016/S0140-6736(09)60827-8

Larkin, J., Flicker, S., Koleszar-Green, R., Mintz, S., Dagnino, M., \& Mitchell, C. (2007). HIV risk, systemic inequities, and aboriginal youth: Widening the circle for HIV prevention programming. Canadian Journal of Public Health, 98(3), 179-182. Retrieved from http://journal.cpha.ca/index.php/ cjph/article/viewFile/811/811

Mann, J. M., \& Carballo, M. (1989). AIDS 1989: Social, cultural and political aspects: Overview. AIDS, 3(Suppl. 1), S221-S223. doi:10.1097/00002030-198901001-00032

Masanjala, W. (2007). The poverty-HIV/AIDS nexus in Africa: A livelihood approach. Social Science \& Medicine, 64(5), 1032-1041. doi:10.1016/j.socscimed.2006.10.009

Mawar, N., Saha, S., Pandit, A., \& Mahajan, U. (2005). The third phase of HIV pandemic: Social consequences of HIV/ AIDS stigma \& discrimination \& future needs. Indian Journal of Medical Research, 122(6), 471-484. Retrieved from http://www.ncbi.nlm.nih.gov/pubmed/16517997

May, K. A. (1991). Interview techniques in qualitative research: Concerns and challenges. In J. M. Morse (Ed.), Qualitative nursing research: A contemporary dialog. Thousand Oaks, CA: Sage.

Mill, J., Austin, W., Chaw-Kant, J., Dumont-Smith, C., Houston, S., Jackson, R., . . Rientjes, F. (2007). The influence of stigma as access to health services by persons with $H I V$ illness. Final Report. Edmonton, Alberta, Canada: University of Alberta.

Mill, J., Edwards, N., Jackson, R., Austin, W., MacLean, L., \& Reintjes, F. (2009). Accessing health services while living with HIV: Intersections of stigma. Canadian Journal of Nursing Research 41(3), 168-185. Retrieved from http:// www.treeofcreation.ca/pdf/challenginglifestyles.pdf

Mill, J. E. (2001). I'm not a 'basabasa' woman: An explanatory model of HIV illness in Ghanaian women. Clinical Nursing Research, 10(3), 254-274. Retrieved from http://www.ingentaconnect.com/content/mcgill/cjnr/2009/ 00000041/00000003/art00012

Mill, J. E. (2003). Shrouded in secrecy: Breaking the news of HIV infection to Ghanaian women. Journal of Transcultural Nursing, 14(1), 6-16. doi:10.1177/1043659602238345

Morse, J. M. (1994). "Emerging from the data": The cognitive processes of analysis in qualitative inquiry. In J. M. Morse (Ed.), Critical issues in qualitative research methods (pp. 23-43). Thousand Oaks, CA: Sage.

Murphy, E. (2001). Micro-level qualitative research. In N. Fulop, P. Allen, A. Clarke, \& N. Black (Eds.), Studying organization and delivery of health services research methods. (pp. 40-55). London: Routledge.

Mwinituo, P. P., \& Mill, J. E. (2006). Stigma associated with Ghanaian caregivers of AIDS patients. Western Journal of Nursing Research, 28(4), 383-391. doi:10.1177/0193945906286602

Nyblade, L. C. (2006). Measuring HIV stigma: Existing knowledge and gaps. Psychology, Health \& Medicine, 11(3), 335-345. doi:10.1080/13548500600595178

Panos Institute. (1990). The 3rd epidemic: Repercussions of the fear of AIDS. London: Author.

Parker, R., \& Aggleton, P. (2003). HIV and AIDS-related stigma and discrimination: A conceptual framework and implications for action. Social Science \& Medicine, 57(1), 13-24. doi:10.1016/S0277-9536(02)00304-0

Paterson, B. L., Backmund, M., Hirsch, G., \& Yim, C. (2007). The depiction of stigmatization in research about hepatitis C. International Journal on Drug Policy, 18(5), 364-373. doi:10.1016/j.drugpo.2007.02.004

Patterson, M., Jackson, R., \& Edwards, N. (2006). Ethics in aboriginal research: Comments on paradigms, process and two worlds. Canadian Journal of Aboriginal CommunityBased HIV/AIDS Research, 1(Summer), 47-57. Retrieved from http://newsite.cbrc.net/attachments/067_CJACBR .pdf\#page $=55$

Pearce, M. E., Christian, W. M., Patterson, K., Norris, K., Moniruzzaman, A., Craib, K., . . Spittal, P. M. (2008). The Cedar Project: Historical trauma, sexual abuse and HIV risk among young aboriginal people who use injection and noninjection drugs in two Canadian cities. Social Science \& Medicine, 66(11), 2185-2194. doi:10.1016/j.socscimed .2008 .03 .034

Public Health Agency of Canada. (2007). HIV/AIDS epi updates, November 2007. Ottawa, ON, Canada: Surveillance and Risk Assessment Division, Centre for Infectious Disease Prevention and Control.

Reidpath, D. D., \& Chan, K. Y. (2005). A method for the quantitative analysis of the layering of HIV-related stigma. AIDS Care, 17(4), 425-432. doi:10.1080/09540120412331319769

Sandelowski, M., Lambe, C., \& Barroso, J. (2004). Stigma in HIV positive women. Journal of Nursing Scholarship, 36(2), 122-128.

Schoepf, B. G. (1994). Action-research and empowerment in Africa. In B. E. Schneider \& N. E. Stoller (Eds.), Women 
resisting AIDS: Feminist strategies of empowerment (pp. 246-269). Philadelphia: Temple University Press.

Scott, A. (2009). Illness meanings of AIDS among women with HIV: Merging immunology and life experience. Qualitative Health Research, 19, 454-465. doi:10.1177/ 1049732309332707

Shapiro, J. (2008). Walking a mile in their patients' shoes: Empathy and othering in medical students' education. Philosophy, Ethics, and Humanities in Medicine: PEHM, 3, 10-21. doi:10.1186/1747-5341-3-10

Siyan'Kela (2006). Stigma resource pack. Policy Project. Pretoria. Center for the Study of AIDS. Retrieved from http:// www.policyproject.com/pubs/countryreports/SA_SRP.pdf

Smylie, J., Kaplan-Myrth, N., Tait, C., Martin, C. M., Chartrand, L., Hogg, W., . . Macaulay, A. C. (2004). Health sciences research and aboriginal communities: Pathway or pitfall? Journal of Obstetrics \& Gynaecology Canada, 26(3), 211-216. Retrieved from http://www.ncbi.nlm.nih.gov/ pubmed/15016333

Sontag, S. (2001). Illness as a metaphor and AIDS and it's metaphors. New York, NY: Picador.

Statistics Canada. (2008). Aboriginal peoples in Canada in 2006: Inuit, Métis and First Nations, 2006 census. Ottawa, ON, Canada: Author.

Stephens, C., Porter, J., Nettleton, C., \& Willis, R. (2006). Disappearing, displaced, and undervalued: A call to action for indigenous health worldwide. Lancet, 367(9527), 2019-2028. doi:10.1016/S0140-6736(06)68892-2

Taylor, B. (2001). HIV, stigma and health: Integration of theoretical concepts and the lived experiences of individuals. Journal of Advanced Nursing, 35(5), 792-798. doi:10.1046/ j.1365-2648.2001.01912.x

Ware, N. C., Wyatt, M. A., \& Tugenberg, T. (2006). Social relationships, stigma and adherence to antiretroviral therapy for HIV/AIDS. AIDS Care, 18(8), 904-910. doi:10.1080/ 09540120500330554
Weiss, M. G., \& Ramakrishna, J. (2001). Interventions: Research on reducing stigma. Retrieved from http://www .stigmaconference.nih.gov/WeissPaper.htm

Wood, M., \& Ross-Kerr, J. C. (2006). Basic steps in planning nursing research: From question to proposal (6th ed.). Sudbury, MA: Jones \& Bartlett.

Worthington, C., \& Myers, T. (2003). Factors underlying anxiety in HIV testing: Risk perceptions, stigma, and the patientprovider power dynamic. Qualitative Health Research, 13, 636-655. doi:10.1177/1049732303013005004

Yang, L. H., Kleinman, A., Link, B. G., Phelan, J. C., Lee, S., $\&$ Good, B. (2007). Culture and stigma: Adding moral experience to stigma theory. Social Science \& Medicine, 64(7), 1524-1535. doi:10.1016/j.socscimed.2006.11.013

\section{Bios}

Judy E. Mill, RN, PhD, is a associate professor and associate dean, Global Health, Faculty of Nursing, University of Alberta, Edmonton, Alberta, Canada.

Nancy Edwards, RN, $\mathrm{PhD}$, is a professor in the School of Nursing and in the Department of Epidemiology and Community Medicine, University of Ottawa, Ottawa, Ontario, Canada. Nancy holds a Nursing Chair from the Canadian Health Services Research Foundation, the Canadian Institutes of Health Research, and the Government of Ontario.

Randy C. Jackson, BA, MA, is a PhD student in the school of Social Work, McMaster University, Hamilton, Ontario, Canada.

Lynne MacLean, $\mathrm{PhD}$, is a research specialist with the Population Health Improvement Research Network, University of Ottawa, Ontario, Canada.

Jean Chaw-Kant, MSc, is a research project coordinator, Faculty of Nursing, University of Alberta, Edmonton, Alberta, Canada. 